\title{
Endothelial PAS domain protein 1 gene hypomethylation is associated with colorectal cancer in Han Chinese
}

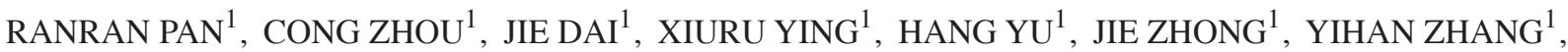 \\ BOYI WU ${ }^{1}$, YIYI MAO ${ }^{1}$, DONGPING WU ${ }^{2}$, JIEER YING ${ }^{3}$, WEI ZHANG ${ }^{4,5}$ and SHIWEI DUAN ${ }^{1}$ \\ ${ }^{1}$ Medical Genetics Center, School of Medicine, Ningbo University, Ningbo, Zhejiang 315211; \\ ${ }^{2}$ Department of Medical Oncology, Shaoxing People's Hospital, Shaoxing, Zhejiang 312000; \\ ${ }^{3}$ Department of Medical Oncology, Zhejiang Cancer Hospital, Hangzhou, Zhejiang 310022, P.R. China; \\ ${ }^{4}$ Department of Preventive Medicine; ${ }^{5}$ The Robert H. Lurie Comprehensive Cancer Center, \\ Northwestern University Feinberg School of Medicine, Chicago, IL 60611, USA
}

Received March 13, 2018; Accepted August 23, 2018

DOI: $10.3892 /$ etm.2018.6856

\begin{abstract}
Endothelial PAS domain-containing protein 1 (EPAS1) serves a role in angiogenesis, which is important for the development of tumors, including colorectal cancer (CRC). The current study aimed to estimate whether EPAS1 methylation was associated with CRC. A two-stage association study of EPAS1 methylation and CRC was conducted. In the first phase, EPASI methylation was evaluated in the tumor and adjacent non-tumor tissue samples from 41 patients with sporadic CRC in Jiangsu province, China. The diagnostic value of methylation of EPASI for CRC in the second phase was evaluated in 79 patients with sporadic CRC and 22 normal individuals in Zhejiang province, China. The methylation assay was performed using a quantitative methylation-specific polymerase chain reaction (qMSP) method. The percentage of methylated reference (PMR) was used to quantify the methylation level. The first-stage results indicated that EPASI promoter methylation was significantly lower in CRC tumor tissues compared with 5-cm-para-tumor tissues (median PMR, 0.59 vs. $1.22 \%$; $\mathrm{P}=0.027$ ) and 10 -cm-para-tumor
\end{abstract}

Correspondence to: Professor Shiwei Duan, Medical Genetics Center, School of Medicine, Ningbo University, 818 Fenghua Road, Ningbo, Zhejiang 315211, P.R. China

E-mail: duanshiwei@nbu.edu.cn

Dr Jieer Ying, Department of Medical Oncology, Zhejiang Cancer Hospital, 38 Guangji Road, Hangzhou, Zhejiang 310022, P.R. China E-mail: jieerying@aliyun.com

Abbreviations: EPAS1, endothelial PAS domain-containing protein 1; CRC, colorectal cancer; qMSP, quantitative methylation-specific polymerase chain reaction; PMR, percent of methylated reference; $\mathrm{CpG}$, cytosine-phosphate-guanine; ROC, receiver operating characteristic

Key words: colorectal cancer, DNA methylation, endothelial PAS domain-containing protein 1 , quantitative methylation-specific polymerase chain reaction tissues (median PMR, 0.59 vs. 1.89\%; $\mathrm{P}=0.001$ ). In addition, the second-stage results indicated that EPAS1 promoter methylation was significantly lower in tumor tissues compared with 5-cm-para-tumor tissues (median PMR, 1.91 vs. 6.25\%; $\left.\mathrm{P}=3 \times 10^{-7}\right)$ and normal intestinal tissues from healthy controls (median PMR, 1.91 vs. $28.4 \%$; $\mathrm{P}=5 \times 10^{-7}$ ). Receiver Operating Characteristic curve analysis of the second-stage data indicated that the highest area under the curve of EPAS1 hypomethylation was 0.851 between Zhejiang CRC tissues and Zhejiang normal intestinal tissues (sensitivity, 95.5\%; specificity, 60.8\%).

\section{Introduction}

In 2015, 376,300 cases of colorectal cancer (CRC) were diagnosed in China (1). CRC is regarded as one of the most common cancers with high morbidity and mortality (2). Despite the improvement of diagnostic technologies, screening tools and clinical therapy, CRC remains a global challenge for public health due to the absence of a 'gold standard' for early diagnosis (2).

The molecular carcinogenic mechanisms of CRC have not been completely elucidated, however, CRC appears to be driven by the accumulation of abnormal genetic and epigenetic alternations in both oncogenes and tumor-suppressor genes (3). Cytosine modification, including DNA methylation, is one of the basic molecular mechanisms involved in the initiation and progression of CRC (2,4-6). Therefore, DNA methylation or epigenetic alterations may be promising markers for the early detection of CRC $(4,7)$.

The endothelium PAS domain protein 1 (EPAS1) gene product is one of the important subunits of oxygen-induced hypoxia inducible factor (HIF) $\alpha$, which regulates the primary transcriptional response to hypoxic stress (8). Hypoxia is one of the main factors promoting tumor angiogenesis $(9,10)$. In addition, angiogenesis is considered a prerequisite for a range of biological processes, including tumorigenesis and tumor progression $(11,12)$. HIF-2 $\alpha /$ EPAS1 serves a role in tumor angiogenesis of different types of cancer, including lung cancer $(13,14)$, renal carcinoma $(15,16)$, liver cancer $(17)$, pheochromocytoma (18-20) and CRC $(8,21)$. 
In a previous study including 39 patients with CRC and 43 normal controls, the expression of EPAS1 in the blood of patients with CRC was significantly increased, and was subsequently decreased after surgical resection of the tumor, returning to a normal level (21). Another study revealed significantly increased levels of EPAS1 methylation and significantly lower levels of EPAS1 mRNA expression in 120 primary colon adenocarcinoma tissues compared with paracancerous tissues (8).

In the current study, quantitative methylation-specific polymerase chain reaction (qMSP) was used to measure EPAS1 methylation in 120 Chinese patients with CRC and 22 healthy controls in two-stage experiments to assess whether the methylation of EPASI could be used as a biomarker for the diagnosis of CRC.

\section{Patients and methods}

Study subjects. The first phase of the association study involved 41 patients with CRC, from whom frozen tumor tissues and adjacent tissues 5 and $10 \mathrm{~cm}$ away from the tumor lesions were collected. These patients with CRC were recruited from the Third Affiliated Hospital of Nanjing University of Traditional Chinese Medicine (Nanjing, China) between August 2011 and March 2015 and their average age was $64.03 \pm 11.39$ years (range, 21-86 years). Of the 41 patients, 28 were male, 12 were female and 1 was missing information. The second phase of the association study was conducted to verify the role of EPASI methylation in CRC. The second phase of the association study involved $79 \mathrm{CRC}$ tumor tissues, 79 paired adjacent tissues $5 \mathrm{~cm}$ away from the tumor lesions and 22 healthy human intestinal tissues. Patients involved in the second phase of the present study were recruited from the Zhejiang Cancer Hospital (Hangzhou, China) and Shaoxing First People's Hospital (Shaoxing, China) between August 2011 and January 2015. The average age of the 79 patients with CRC in the second phase of the present association study was $60.27 \pm 11.74$ years. Of the 79 patients, 51 were male and 28 were female. All patients were diagnosed by pathological examination. No radiotherapy or chemotherapy was performed prior to surgery. The age and sex data of healthy controls were not available. All clinical data were extracted between August 2011 and March January 2015 from medical records for subsequent analysis. The Human Research Ethics Committee of Ningbo University (Ningbo, China) granted approval for the present study. Each participant completed the written informed consent form.

DNA extraction and bisulfite conversion. DNA was extracted from frozen tissues using E.Z.N.A. ${ }^{\circledR}$ Tissue DNA kit (Omega Bio-Tek, Inc., Norcross, GA, USA) according to the manufacturer's protocol. DNA concentrations measurement and bisulfite treatment were performed as previously described (22).

SYBR-Green-based qMSP. qMSP was performed as previously described $(23,24)$. The following thermocycling conditions were used: Initial denaturation at $95^{\circ} \mathrm{C}$ for $10 \mathrm{~min}$; 45 cycles of $95^{\circ} \mathrm{C}$ for $20 \mathrm{sec}, 58^{\circ} \mathrm{C}$ for $20 \mathrm{sec}$ and $72^{\circ} \mathrm{C}$ for $30 \mathrm{sec}$; melting curve analysis at $95^{\circ} \mathrm{C}$ for $15 \mathrm{sec}, 58^{\circ} \mathrm{C}$ for $1 \mathrm{~min}$ and $60^{\circ} \mathrm{C}$ for $1 \mathrm{~min}$; and a final cooling stage at $40^{\circ} \mathrm{C}$ for $10 \mathrm{~min}$. The primer sequences for EPAS1 (95 bp) were forward, 5'-GTTATAGATAGCGTTTGTAGAC-3' and reverse, 5'-GATTACCACATTCCCGATA-3'; and the primer sequences for $A C T B(133 \mathrm{bp})$ were forward, 5'-TGGTGA TGGAGGAGGTTTAGTAAGT-3' and reverse, 5'-AACCAA TAAAACCTACTCCTCCCTTAA-3'. The percentage of methylated reference (PMR) of EPAS1 for each sample was calculated using the $2^{-\Delta \Delta \mathrm{Cq}}$ quantification approach, where $\triangle \triangle \mathrm{Cq}=$ sample DNA $\left(\mathrm{Ct}_{E P A S I}-\mathrm{Ct}_{A C T B \text { control }}\right)$-fully methylated DNA $\left(\mathrm{Ct}_{\text {EPASI }}-\mathrm{Ct}_{\text {ACTB control }}\right)$ (25).

Bioinformatics analysis. The genomic position of the amplified fragment was obtained from University of California Santa Cruz genome browser according to human (GRCh37) assembly (genome.ucsc.edu). To evaluate the association between mRNA expression and EPAS1 methylation, data in the TCGA colorectal adenocarcinoma cohort with 372 samples were downloaded from cBioPortal (www.cbioportal.org).

Statistical analysis. All data were analyzed using SPSS 18.0 software (SPSS Inc., Chicago, IL, USA). Due to the skewed distribution of methylation levels, data were presented as the median (interquartile range). Friedman test and Wilcoxon nonparametric testwere used toassess the differenceinmethylation between samples. Mann-Whitney U nonparametric test was used to assess the difference in methylation between groups. Contingency correlation test was used to evaluate the association between EPAS1 methylation and clinical features. Spearman's rank correlation coefficient was used to assess the correlation between EPAS1 methylation and gene expression. Pearson $\chi^{2}$ test or Fisher's exact test were used to assess the difference in clinical features between different sampling locations. The receiver operating characteristic (ROC) analysis was used to evaluate the diagnostic value of EPAS1 promoter methylation for CRC. Two-tailed $\mathrm{P}<0.05$ was considered to indicate a statistically significant difference. All figures were plotted using GraphPad Prism 5.0 software (GraphPad Software, Inc., La Jolla, CA, USA). Sequencing results were analyzed using Chromas LITE 2.1.1 software (Technelysium Pty, Ltd., Brisbane, Australia).

\section{Results}

DNA methylation analysis. To assess the association between methylation of EPAS1 and CRC, a two-stage association study was conducted. Two cytosine-phosphate-guanine $(\mathrm{CpG})$ sites were identified in the 95 bp fragment of EPAS1 (hg38; chr2:46 526691-46526785) (Fig. 1A). The tested EPAS1 fragment was expected to be $95 \mathrm{bp}$ (Fig. 1B). Sequencing results indicated that the amplified fragment matched the target sequence (Fig. 1C).

Association between EPAS1 hypomethylation in patients with $C R C$ and clinical features. The results of the present study indicated that the EPAS1 methylation was not associated with sex, age, TNM stage, differentiation, tumor size or lymph node metastasis (all P>0.05) (Table I). Methylation levels in the tissues from 41 patients with CRC (Jiangsu, China) and 79 patients with CRC (Zhejiang, China) were examined. The results indicated that EPAS1 promoter methylation levels in CRC tissues (Jiangsu, China) were significantly lower compared with those of the 5-cm-para-tumor tissues (median PMR, 0.59 vs. $1.22 \% ; \mathrm{P}=0.027$ ) (Fig. $2 \mathrm{~A}$ ) and $10-\mathrm{cm}$-para-tumor 
प198
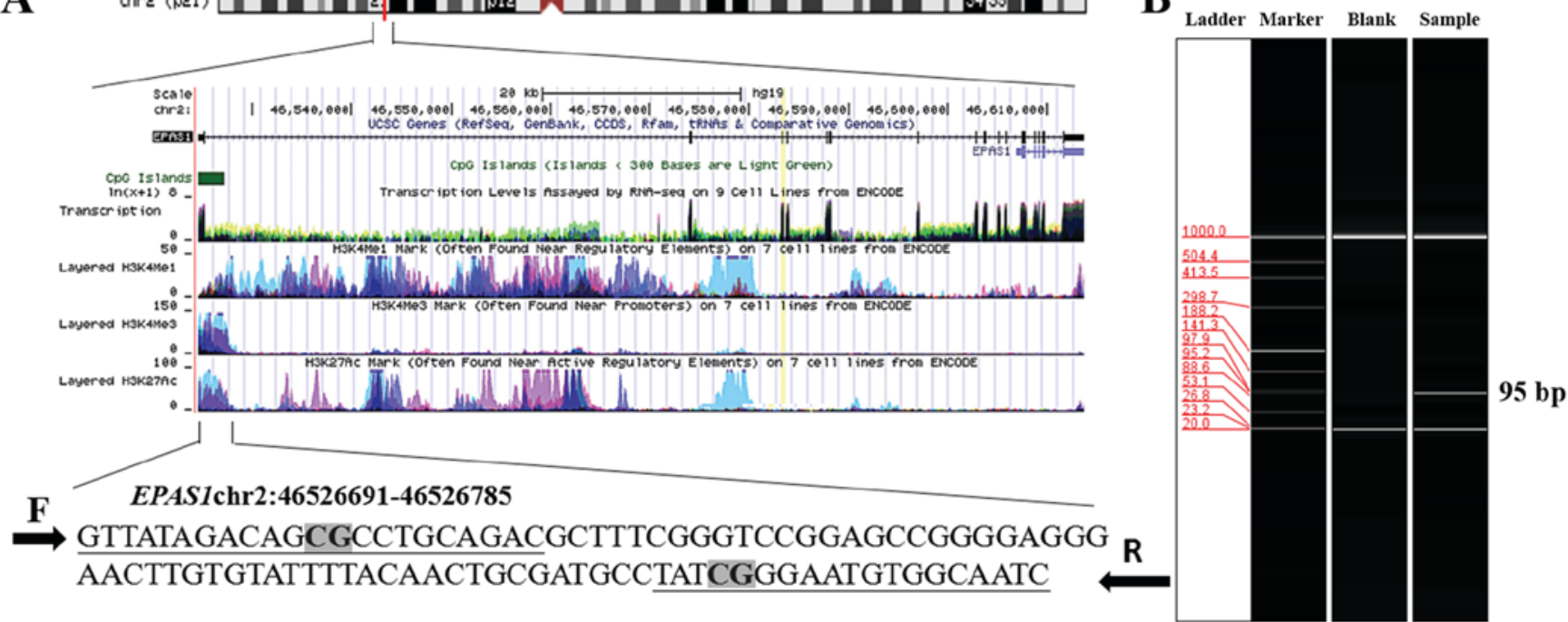

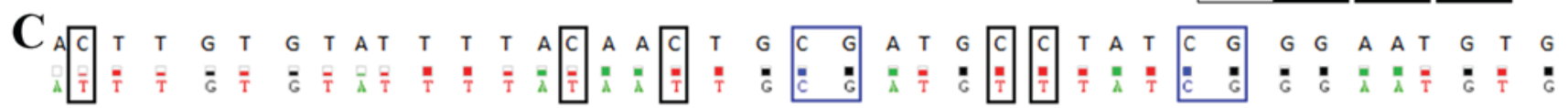
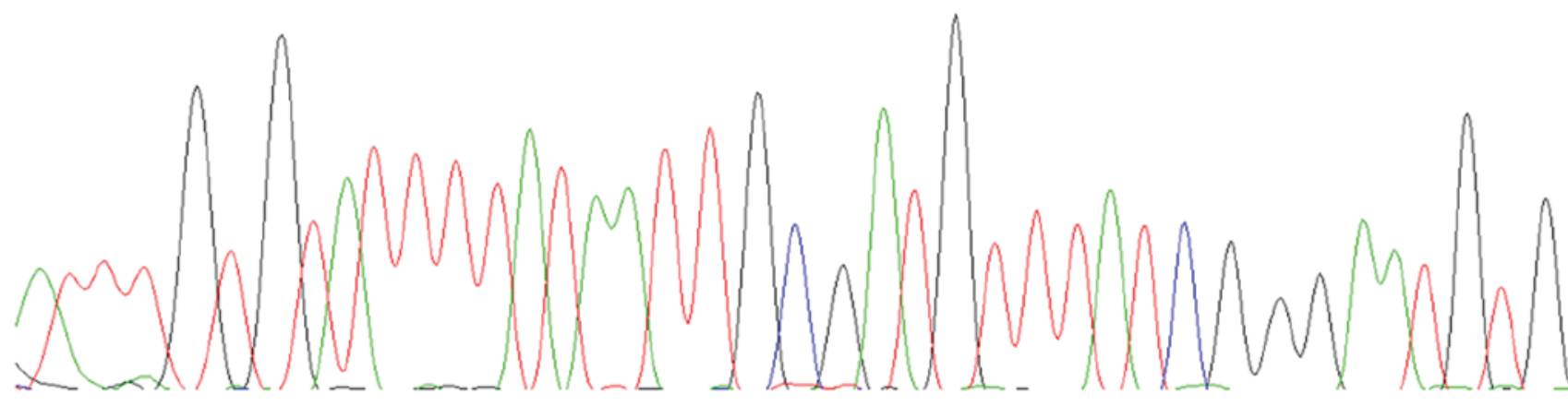

Figure 1. Characteristics of the target sequence in EPAS1. (A) Target sequences in EPAS1 promoter region. The genomic position of the amplified fragment from University of California Santa Cruz genome browser according to human (GRCh37) assembly. The primers are underlined and two CpG sites are presented in bold fond with grey highlight. (B) Capillary electrophoresis for the amplified fragment ( $95 \mathrm{bp})$. (C) Sanger sequencing results. The top row of the sequence is the original sequence of the fragment. The bottom row of the sequence is the converted sequence; CG dinucleotides that remained unaltered are in blue boxes; and $\mathrm{C}$ nucleotides with corresponding converted T nucleotides are in black boxes. F, forward primer; R, reverse primer; EPAS1, endothelial PAS domain-containing protein $1 ; \mathrm{CpG}$, cytosine-phosphate-guanine.

tissues (median PMR, 0.59 vs. 1.89\%; $\mathrm{P}=0.001$ ) (Fig. 2A). Second-stage experiment was used to further validate the role of EPAS1 methylation in CRC. The results indicated that EPAS1 promoter methylation was significantly lower in CRC tissues (Zhejiang, China) compared with 5-cm-para-tumor tissues (median PMR, 1.91 vs. 6.25\%; $\mathrm{P}=3 \times 10^{-7}$ ) (Fig. 2B) and normal intestinal tissues from healthy controls (median PMR, 1.91 vs. $28.84 \%$; $\mathrm{P}=5 \times 10^{-7}$ ) (Fig. $2 \mathrm{~B}$ ). Additionally, a significantly lower EPASI promoter methylation was found in the paired 5-cm-para-tumor tissues (Zhejiang, China) compared with normal intestinal tissues of healthy controls (median PMR, 6.25 vs. $28.84 \%$; $\mathrm{P}=0.028$ ) (Fig. $2 \mathrm{~B}$ ). A negative correlation between mRNA expression and EPAS1 methylation was identified in 372 TCGA colorectal adenocarcinoma samples $\left(\mathrm{r}=-0.329, \mathrm{P}=8 \times 10^{-11}\right)$ ( Fig. 3).

The present study demonstrated that EPASI methylation levels of tumor tissues from patients from Zhejiang province were significantly higher compared with tumor tissues from Jiangsu province (median PMR, 1.91 vs. $0.59 \% ; \mathrm{P}=4 \times 10^{-7}$ ) (Table II). Significantly higher EPAS1 methylation levels were observed in the adjacent non-tumor tissues from patients from Zhejiang province compared with patients from Jiangsu province (median PMR, 6.25 vs. $1.22 \%$; $\mathrm{P}=4 \times 10^{-7}$ ) (Table II). However, the difference in EPASl methylation levels between tumor and non-tumor tissues ( $\left.\mathrm{D}=\mathrm{PMR}_{\text {tumor }}-\mathrm{PMR}_{\text {non-tumor }}\right)$ was not significant between Jiangsu province and Zhejiang province $(\mathrm{P}=0.066)$ (Table III). To clarify the differences in methylation status between the two provinces, the present study further investigated the association between sample locations and the clinical phenotypes of patients with CRC. The results indicated that there was a significant difference in the age at diagnosis between Zhejiang $(57 / 79 ; 72.2 \%)$ compared with Jiangsu $(21 / 41,51.2 \%)\left(\chi^{2}=4.541 ; \mathrm{P}=0.033\right)$ (Table III). In addition, there was statistically significant difference in differentiation between Jiangsu and Zhejiang province $(\mathrm{P}=0.002)$ (Table III). However, there were no significant differences in EPASI methylation levels between age subgroups and between differentiation subgroups in both provinces $(\mathrm{P}>0.05)$ (Table II).

ROC curve analysis. ROC curve analysis was used to measure the diagnostic value of EPASI hypomethylation for CRC. The second-stage association results indicated 


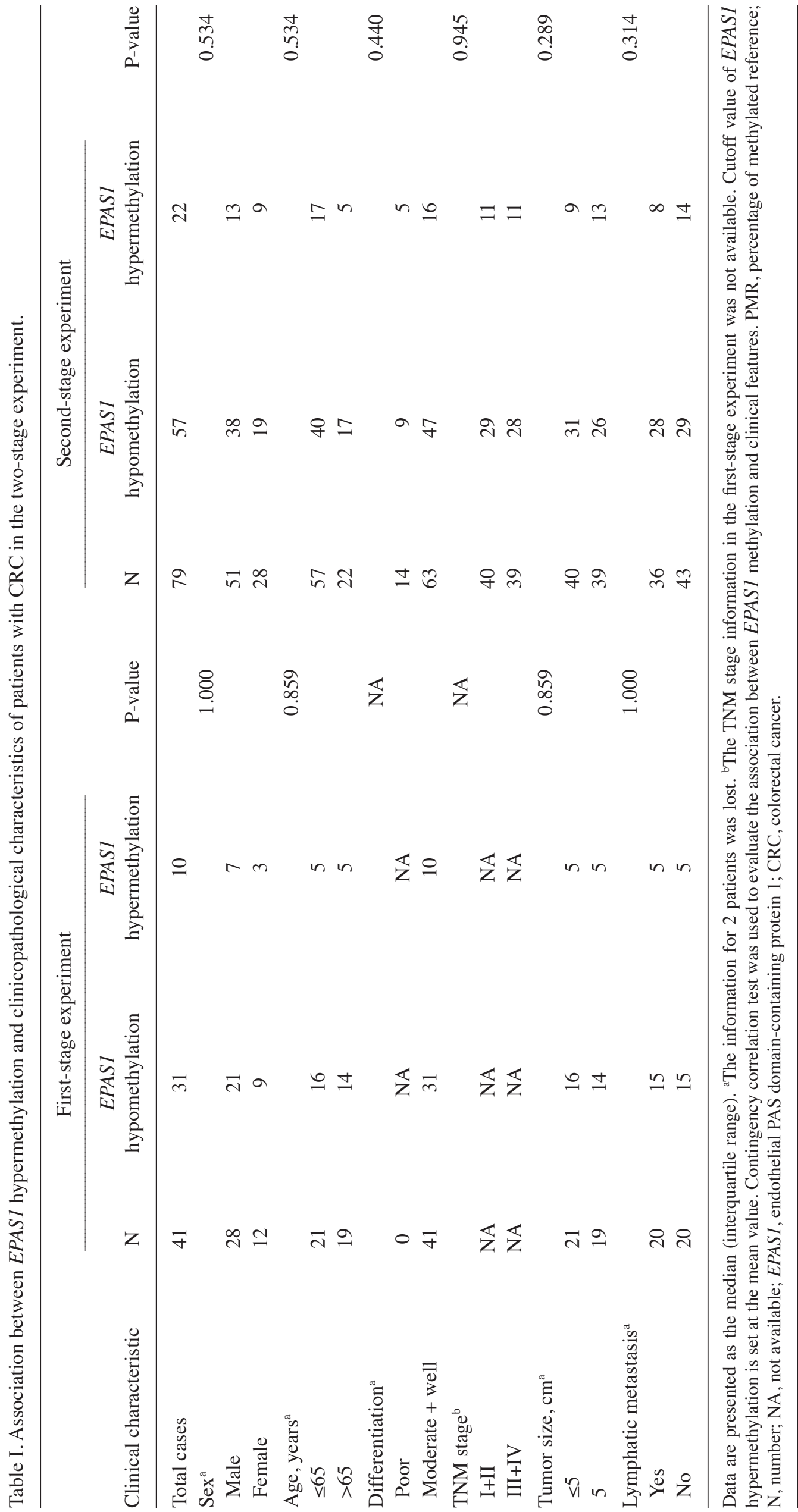


Table II. Subgroup analysis by age and differentiation.

\begin{tabular}{|c|c|c|c|c|c|c|}
\hline \multirow[b]{2}{*}{ Variable } & \multicolumn{2}{|c|}{ Tumor PMR (\%) } & \multirow[b]{2}{*}{ P-value } & \multicolumn{2}{|c|}{ Non-tumor PMR (\%) } & \multirow[b]{2}{*}{ P-value } \\
\hline & Jiangsu & Zhejiang & & Jiangsu & Zhejiang & \\
\hline Total & $0.59(0.35,1.19)$ & $1.91(0.79,4.90)$ & $4 \times 10^{-7}$ & $1.22(0.63,2.11)$ & $6.25(2.35,29.63)$ & $4 \times 10^{-7}$ \\
\hline \multicolumn{7}{|l|}{ Age, years } \\
\hline$\leq 65$ & $0.83(0.38,1.54)$ & $1.91(0.83,5.22)$ & 0.008 & $1.06(0.56,1.92)$ & $7.35(7.24,30.43)$ & $3 \times 10^{-6}$ \\
\hline$>65$ & $0.48(0.28,1.24)$ & $1.83(0.65,4.02)$ & 0.009 & $1.53(0.69,2.27)$ & $3.90(2.33,24.86)$ & $2 \times 10^{-4}$ \\
\hline P-value & 0.236 & 0.577 & & 0.630 & 0.418 & \\
\hline \multicolumn{7}{|l|}{ Differentiation } \\
\hline Poor & NA & $2.39(1.28,6.03)$ & NA & NA & $9.16(2.32,39.14)$ & NA \\
\hline Moderate + well & $0.59(0.35,1.19)$ & $1.89(0.79,4.72)$ & $2 \times 10^{-4}$ & $1.22(0.60,2.18)$ & $6.19(2.35,29.63)$ & $8 \times 10^{-9}$ \\
\hline P-value & NA & 0.235 & & NA & 0.530 & \\
\hline
\end{tabular}

Mann-Whitney U nonparametric test were used to assess the difference in methylation between groups. NA, not available; PMR, percentage of methylated reference.
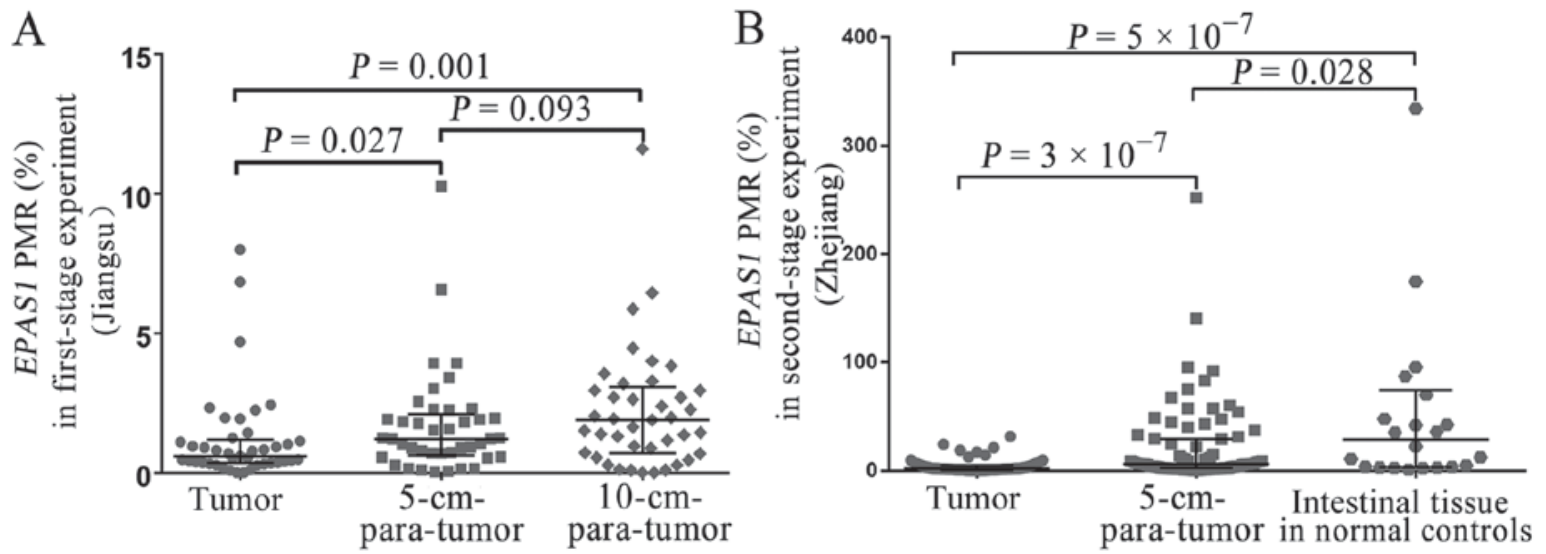

Figure 2. Comparisons of EPAS1 methylation levels between patients and normal controls. (A) Comparisons of methylation levels between tumor tissues, 5-cm-para-tumor tissues and 10-cm-para-tumor tissues (Jiangsu, China). (B) Comparisons of methylation levels between tumor tissues, 5-cm-para-tumor tissues and normal intestinal tissues of healthy controls (Zhejiang, China). EPAS1, endothelial PAS domain-containing protein 1; PMR, percentage of methylated reference.

that EPAS1 hypomethylation yielded a significant AUC of 0.731 (95\% CI, 0.653-0.808) with a sensitivity of $58.2 \%$ and a specificity of $78.5 \%$ between cancer tissues and 5-cm-para-tumor tissues (Fig. 4A); a significant AUC of 0.851 (95\% CI, $0.760-0.942)$ with a sensitivity of $95.5 \%$ and a specificity of $60.8 \%$ between CRC tissues and normal intestinal tissues of healthy controls (Fig. 4B); and a significant AUC of 0.654 (95\% CI, 0.522-0.786) with a sensitivity of $63.6 \%$ and a specificity of $65.8 \%$ between 5-cm-para-tumor tissues and normal intestinal tissues of healthy controls (Fig. 4C). All of the above data supported the hypothesis that hypomethylation of EPAS1 may be a potential diagnostic biomarker for CRC.

\section{Discussion}

CRC is regarded as a threat to human health (2), and the study of methylation in the context of CRC is a field of growing interest. In the present study, EPASI promoter methylation significantly decreased according to the results of both the first-stage and the second-stage association tests. These results

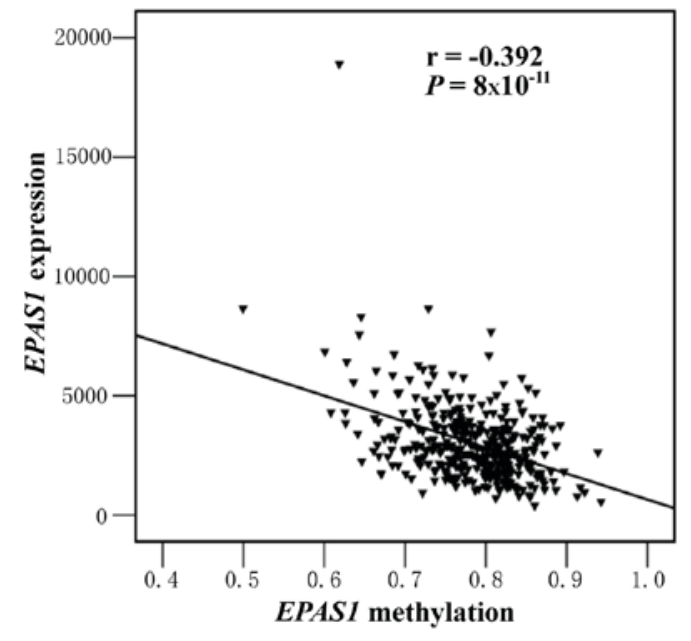

Figure 3. Bioinformatics analysis of the correlation between EPASI methylation and expression. An inverse correlation was identified between EPAS1 methylation and mRNA expression in 372 colorectal cancer samples $\left(\mathrm{r}=-0.329, \mathrm{P}=8 \times 10^{-11}\right) . E P A S 1$, endothelial PAS domain-containing protein 1 . 
Table III. Association between sampling location and clinical characteristics.

\begin{tabular}{|c|c|c|c|c|}
\hline Clinical characteristic & Number & Jiangsu & Zhejiang & P-value \\
\hline Total cases & 120 & 41 & 79 & \\
\hline $\operatorname{Sex}^{\mathrm{a}}$ & & & & $0.553^{\mathrm{b}}$ \\
\hline Male & 79 & 28 & 51 & \\
\hline Female & 40 & 12 & 28 & \\
\hline Age, years ${ }^{\mathrm{a}}$ & & & & $0.033^{\mathrm{b}}$ \\
\hline$\leq 65$ & 78 & 21 & 57 & \\
\hline$>65$ & 41 & 19 & 22 & \\
\hline Tumor size ${ }^{a}$ & & & & $0.847^{\mathrm{b}}$ \\
\hline$<5 \mathrm{~cm}$ & 61 & 21 & 40 & \\
\hline$\geq 5 \mathrm{~cm}$ & 58 & 19 & 39 & \\
\hline Differentiation $^{\mathrm{a}}$ & & & & $0.002^{\mathrm{c}}$ \\
\hline Low and none & 14 & 0 & 14 & \\
\hline High and medium & 103 & 40 & 63 & \\
\hline Lymph node metastasis ${ }^{a}$ & & & & $0.842^{\mathrm{b}}$ \\
\hline Negative & 55 & 19 & 36 & \\
\hline Positive & 64 & 21 & 43 & \\
\hline EPAS1 methylation & & & & $0.066^{\mathrm{b}}$ \\
\hline Hypomethylation & 91 & 27 & 64 & \\
\hline Hypermethylation & 29 & 14 & 15 & \\
\hline
\end{tabular}

${ }^{a}$ The information for 1 patient was lost. ${ }^{b}$ Data analyzed using Pearson $\chi^{2}$ test. ${ }^{c}$ Data analyzed using Fisher's exact test. Hypermethylation was determined to be present if PMR detected in the tumor tissue was higher than in the matched normal sample. Hypomethylation was determined to be present in the inverse case. EPAS1, endothelial PAS domain-containing protein 1.
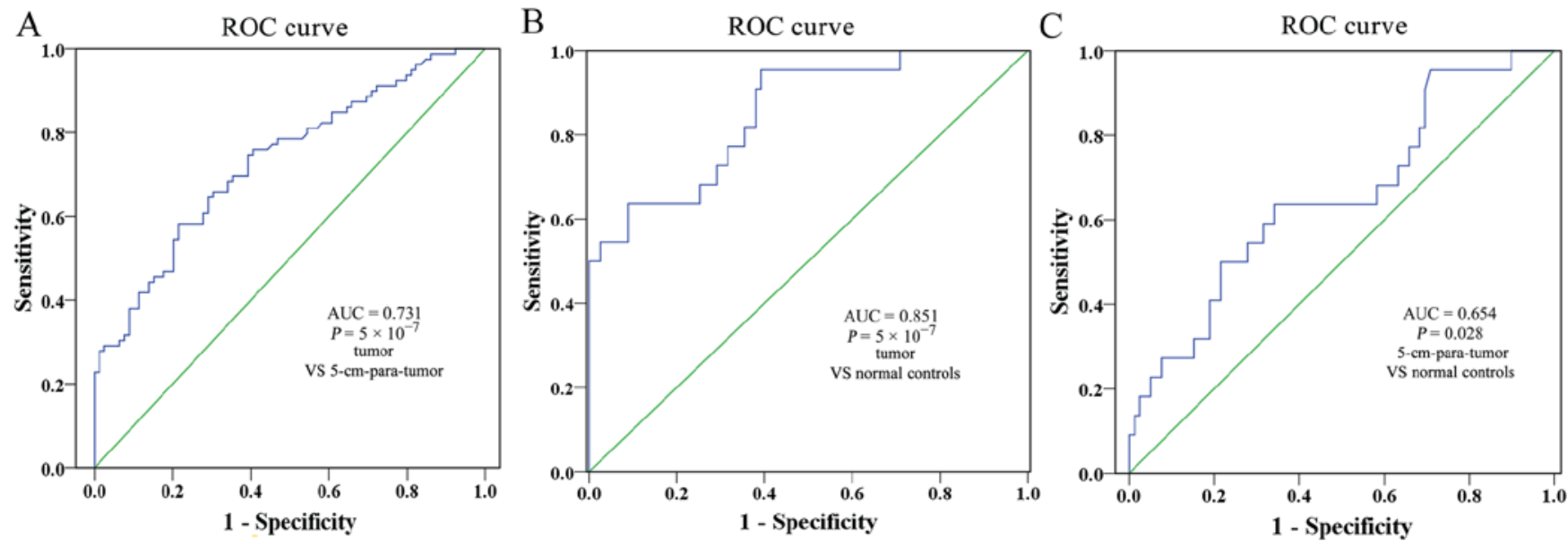

Figure 4. ROC curves for the diagnostic value of EPASI hypomethylation in the second-stage experiment. (A) ROC curve for the diagnostic value of EPASI hypomethylation between CRC tissues and paired non-cancer tissues (Zhejiang, China). (B) ROC curve for the diagnostic value of EPAS1 hypomethylation between CRC tissues and normal intestinal tissues of healthy controls (Zhejiang, China). (C) ROC curve for the diagnostic value of EPAS1 hypomethylation between paired non-cancer tissues and normal intestinal tissues of healthy controls (Zhejiang, China). ROC, receiver operating characteristic; AUC, area under the curve; EPAS1, endothelial PAS domain-containing protein 1; CRC, colorectal cancer.

led to a hypothesis that EPASI hypomethylation may be associated with the development of CRC. In the subsequent experiment, EPAS1 hypomethylation yielded an AUC of 0.851 (sensitivity, 95.5\%; specificity, 60.8\%) to distinguish the CRC tumor tissues from normal intestinal tissues, suggesting that EPAS1 hypomethylation could serve as a promising diagnostic biomarker for CRC.
Numerous studies demonstrated that EPAS1 served a role in angiogenesis of human cancer (26-28) at the post-transcriptional level (27). Yoshimura et al (11) demonstrated that EPAS1 was overexpressed in aggressive colorectal carcinoma and exhibited a significant direct correlation with tumor microvessel count. Cho et al (16) identified that EPAS1 was bound by TP2399 in the PAS B domain, which diminished its ability to bind to 
ARNT, causing tumor regression in preclinical kidney cancer models. This means that EPAS1 might be an important factor in the processes of tumorigenesis and cancer progression. In human breast cancer cells, methyl-CpG-binding domain protein 3 can remove the methylation of $\mathrm{CpG}$ sites near the promoter of EPAS1, and, therefore, significantly increase the expression of EPAS1 (27). In epithelial cells, DNA (cytosine-5)-methyltransferase 3A (DNMT3A) can silence the expression of EPAS1 (29,30). DNMT3A deficiencies were reported in primary tumors and malignant cells, leading to demethylation of EPAS1 promoter (31) and resulting in the growth of cancer cells under hypoxia (31-34). Re-introducing DNMT3A can restore the silencing of EPAS1, and prevent cell proliferation and viability under hypoxia, inhibiting tumor occurrence $(8,31)$. In addition, our data mining of The Cancer Genome Atlas database discovered that there was an inverse EPAS1 methylation-expression correlation in different cancers. Therefore, the present study further hypothesized that angiogenesis induced by increased expression of EPAS1 could be a reason underlying the occurrence of CRC. Future studies should verify the function of EPAS1 in CRC.

Although several types of biomarkers have been studied in CRC (35,36), a biomarker for early diagnosis remains to be identified. Carcinoembryonic antigen (CEA), a biomarker used globally, did not exhibit the desired diagnostic value according to one study (37). However, Peng et al (38) reported an AUC of 0.690 for CEA in the detection of CRC. In addition, there are two main methods widely used in clinical diagnosis of CRC, including fecal occult blood test (FOBT) and colonoscopy (37). However, FOBT is susceptible to bias resulting from external factors including drugs and diet, and colonoscopy is associated with significant costs and can often cause pain (37). The present qMSP-based study indicated an AUC of 0.851 (sensitivity, 95.5\%; specificity, 60.8\%) between CRC tissues and normal intestinal tissues of healthy controls.

A previous study indicated that patients with CRC exhibited significantly elevated EPAS1 expression in blood, which decreased significantly to normal levels following surgical resection of the tumor (21). Further analyses of EPASI methylation in blood samples of patients with CRC before and after surgery should be conducted to further verify the diagnostic value of EPAS1 hypomethylation.

Benign colorectal disease can gradually progress to advanced adenoma and, subsequently, to invasive adenocarcinoma (39-41). In addition, aberrant methylation patterns exhibit a malignant potential in hyperplastic polyps (39-42). Numerous studies have indicated that there were significant differences in DNA methylation levels between CRC tissues, benign colorectal disease tissues and healthy intestinal tissues (43-45). However, methylation data for benign colorectal disease were not available in the present study. Further investigation is necessary to determine whether EPAS1 methylation serves a role in benign colorectal disease.

Plasma circulating DNA (cell-free DNA) of patients with cancer may originate from circulating tumor cells, which can indicate the occurrence of micrometastasis and invasion of cancer cells $(46,47)$. The present study indicated that the levels of EPAS1 methylation in the tumor tissues were lower compared with the adjacent non-tumor tissues. The detection of EPAS1 methylation in plasma cf-DNA could be performed in the future to avoid variation resulting from differences in tissue sampling sites, surgical techniques and so on.

In conclusion, the present study suggested that EPAS1 hypomethylation may be a diagnostic biomarker for CRC. Further study is necessary to clarify the molecular mechanisms by which EPAS1 hypomethylation may exert its role in carcinogenesis.

\section{Acknowledgements}

Not applicable.

\section{Funding}

The research was supported in part by K.C. Wong Magna Fund in Ningbo University (to SD) and grant no. U01CA217078 in Northwestern University (to WZ).

\section{Availability of data and materials}

Not applicable.

\section{Authors' contributions}

SD and RP conceived and designed the experiments. JY, DW, CZ, XY, JZ, HY, JD, BW, YM and YZ performed the experiments. RP, CZ and HY analyzed the data. RP, WZ and SD contributed to the completion of figures and tables, and writing of the manuscript.

\section{Ethics approval and consent to participate}

Not applicable.

\section{Patient consent for publication}

Not applicable.

\section{Competing interests}

The authors declare that they have no competing interests.

\section{References}

1. Chen W, Zheng R, Baade PD, Zhang S, Zeng H, Bray F, Jemal A, Yu XQ and He J: Cancer statistics in China, 2015. CA Cancer J Clin 66: 115-132, 2016.

2. Brenner H, Kloor M and Pox CP: Colorectal cancer. Lancet 383: 1490-1502, 2014

3. Carethers JM and Jung BH: Genetics and genetic biomarkers in sporadic colorectal cancer. Gastroenterology 149: 1177-1190.e3, 2015.

4. Okugawa Y, Grady WM and Goel A: Epigenetic alterations in colorectal cancer: Emerging biomarkers. Gastroenterology 149: 1204-1225.e12, 2015.

5. Zhou D, Tang W, Su G, Cai M, An HX and Zhang Y: PCDH18 is frequently inactivated by promoter methylation in colorectal cancer. Sci Rep 7: 2819, 2017

6. Rezvani N, Alibakhshi R, Vaisi-Raygani A, Bashiri H and Saidijam M: Detection of SPG20 gene promoter-methylated DNA, as a novel epigenetic biomarker, in plasma for colorectal cancer diagnosis using the MethyLight method. Oncol Lett 13: 3277-3284, 2017

7. Li W, Zhang X, Lu X, You L, Song Y, Luo Z, Zhang J, Nie J, Zheng W, Xu D, et al: 5-Hydroxymethylcytosine signatures in circulating cell-free DNA as diagnostic biomarkers for human cancers. Cell Res 27: 1243-1257, 2017. 
8. Rawłuszko-Wieczorek AA,Horbacka K, Krokowicz P, Misztal M and Jagodziński PP: Prognostic potential of DNA methylation and transcript levels of HIF1A and EPAS1 in colorectal cancer. Mol Cancer Res 12: 1112-1127, 2014.

9. Tian H, McKnight SL and Russell DW: Endothelial PAS domain protein 1 (EPAS1), a transcription factor selectively expressed in endothelial cells. Genes Dev 11: 72-82, 1997.

10. Robins JC, Akeno N, Mukherjee A, Dalal RR, Aronow BJ, Koopman $P$ and Clemens TL: Hypoxia induces chondrocyte-specific gene expression in mesenchymal cells in association with transcriptional activation of Sox9. Bone 37: 313-322, 2005

11. Yoshimura H, Dhar DK, Kohno H, Kubota H, Fujii T, Ueda S, Kinugasa S, Tachibana M and Nagasue N: Prognostic impact of hypoxia-inducible factors 1alpha and 2alpha in colorectal cancer patients: Correlation with tumor angiogenesis and cyclooxygenase-2 expression. Clin Cancer Res 10: 8554-8560, 2004.

12. Tanigawa N, Amaya H, Matsumura M, Lu C, Kitaoka A, Matsuyama K and Muraoka R: Tumor angiogenesis and mode of metastasis in patients with colorectal cancer. Cancer Res 57: 1043-1046, 1997.

13. Putra AC, Eguchi H, Lee KL, Yamane Y, Gustine E, Isobe T, Nishiyama M, Hiyama K, Poellinger L and Tanimoto K: The A Allele at rs13419896 of EPAS1 is associated with enhanced expression and poor prognosis for non-small cell lung cancer. PLoS One 10: e0134496, 2015.

14. Iwamoto S, Tanimoto K, Nishio Y, Putra AC, Fuchita H, Ohe M, Sutani A, Kuraki T, Hiyama K, Murakami I, et al: Association of EPAS1 gene rs4953354 polymorphism with susceptibility to lung adenocarcinoma in female Japanese non-smokers. J Thorac Oncol 9: 1709-1713, 2014.

15. Xia G, Kageyama Y, Hayashi T, Kawakami S, Yoshida M and Kihara K: Regulation of vascular endothelial growth factor transcription by endothelial PAS domain protein 1 (EPAS1) and possible involvement of EPAS1 in the angiogenesis of renal cell carcinoma. Cancer 91: 1429-1436, 2001.

16. Cho H, Du X, Rizzi JP, Liberzon E, Chakraborty AA, Gao W, Carvo I, Signoretti S, Bruick RK, Josey JA, et al: On-target efficacy of a HIF-2 $\alpha$ antagonist in preclinical kidney cancer models. Nature 539: 107-111, 2016.

17. Sena JA, Wang L, Heasley LE and Hu CJ: Hypoxia regulates alternative splicing of HIF and non-HIF target genes. Mol Cancer Res 12: 1233-1243, 2014.

18. Welander J, Andreasson A, Brauckhoff M, Bäckdahl M, Larsson C, Gimm O and Söderkvist P: Frequent EPAS1/HIF2 $\alpha$ exons 9 and 12 mutations in non-familial pheochromocytoma. Endocr Relat Cancer 21: 495-504, 2014.

19. Baba Y, Nosho K, Shima K, Irahara N, Chan AT, Meyerhardt JA, Chung DC, Giovannucci EL, Fuchs CS and Ogino S: HIF1A overexpression is associated with poor prognosis in a cohort of 731 colorectal cancers. Am J Pathol 176: 2292-2301, 2010.

20. Favier J, Plouin PF, Corvol P and Gasc JM: Angiogenesis and vascular architecture in pheochromocytomas: Distinctive traits in malignant tumors. Am J Pathol 161: 1235-1246, 2002.

21. Collado M, Garcia V, Garcia JM, Alonso I, Lombardia L, Diaz-Uriarte R, Fernández LA, Zaballos A, Bonilla F and Serrano M: Genomic profiling of circulating plasma RNA for the analysis of cancer. Clin Chem 53: 1860-1863, 2007.

22. Chen X, Yang Y, Liu J, Li B, Xu Y, Li C, Xu Q, Liu G, Chen Y, Ying J and Duan S: NDRG4 hypermethylation is a potential biomarker for diagnosis and prognosis of gastric cancer in Chinese population. Oncotarget 8: 8105-8119, 2017.

23. Li B, Chen X, Jiang Y, Yang Y, Zhong J, Zhou C, Hu H and Duan S: CCL2 promoter hypomethylation is associated with gout risk in Chinese Han male population. Immunol Lett 190: 15-19, 2017.

24. Yang Y, Chen X, Hu H, Jiang Y, Yu H, Dai J, Mao Y and Duan S: Elevated UMOD methylation level in peripheral blood is associated with gout risk. Sci Rep 7: 11196, 2017.

25. Kristensen LS, Mikeska T, Krypuy M and Dobrovic A: Sensitive melting analysis after real time-methylation specific PCR (SMART-MSP): High-throughput and probe-free quantitative DNA methylation detection. Nucleic Acids Res 36: e42, 2008.

26. Zhang Q, Lou Y, Zhang J, Fu Q, Wei T, Sun X, Chen Q, Yang J, Bai X and Liang T: Hypoxia-inducible factor-2 $\alpha$ promotes tumor progression and has crosstalk with Wnt/ $\beta$-catenin signaling in pancreatic cancer. Mol Cancer 16: 119, 2017.

27. Cui J, Duan B, Zhao X, Chen Y, Sun S, Deng W, Zhang Y, Du J, Chen Y and Gu L: MBD3 mediates epigenetic regulation on EPAS1 promoter in cancer. Tumour Biol 37: 13455-13467, 2016.
28. Zhu DM, Li DC, Zhang ZX and Zhang XY: Effect of endothelia PAS domain protein 1 and hypoxia inducible factor lalpha on vascular endothelial growth factor expression in human pancreatic carcinoma. Chin Med J (Engl) 121: 2258-2264, 2008.

29. Talks KL, Turley H, Gatter KC, Maxwell PH, Pugh CW, Ratcliffe PJ and Harris AL: The expression and distribution of the hypoxia-inducible factors HIF-1alpha and HIF-2alpha in normal human tissues, cancers, and tumor-associated macrophages. Am J Pathol 157: 411-421, 2000.

30. Kim CM, Vocke C, Torres-Cabala C, Yang Y, Schmidt L, Walther M and Linehan WM: Expression of hypoxia inducible factor-1alpha and 2alpha in genetically distinct early renal cortical tumors. J Urol 175: 1908-1914, 2006.

31. Lachance G, Uniacke J, Audas TE, Holterman CE, Franovic A, Payette J and Lee S: DNMT3a epigenetic program regulates the HIF-2 $\alpha$ oxygen-sensing pathway and the cellular response to hypoxia. Proc Natl Acad Sci USA 111: 7783-7788, 2014.

32. Gordan JD, Bertout JA, Hu CJ, Diehl JA and Simon MC: HIF-2alpha promotes hypoxic cell proliferation by enhancing c-myc transcriptional activity. Cancer Cell 11: 335-347, 2007.

33. Kim WY, Perera S, Zhou B, Carretero J, Yeh JJ, Heathcote SA, Jackson AL, Nikolinakos P, Ospina B, Naumov G, et al: HIF2alpha cooperates with RAS to promote lung tumorigenesis in mice. J Clin Invest 119: 2160-2170, 2009.

34. Franovic A, Holterman CE, Payette J and Lee S: Human cancers converge at the HIF-2alpha oncogenic axis. Proc Natl Acad Sci USA 106: 21306-21311, 2009.

35. Ravegnini G, Zolezzi Moraga JM, Maffei F, Musti M,Zenesini C, Simeon V, Sammarini G, Festi D, Hrelia P and Angelini S: Simultaneous analysis of SEPT9 promoter methylation status, micronuclei frequency, and folate-related gene polymorphisms: The potential for a novel blood-based colorectal cancer biomarker. Int J Mol Sci 16: 28486-28497, 2015.

36. Huang J, Tan ZR, Yu J, Li H, Lv QL, Shao YY and Zhou HH: DNA hypermethylated status and gene expression of PAX1/SOX1 in patients with colorectal carcinoma. OncoTargets Ther 10: 4739-4751, 2017.

37. Li Y, Song L, Gong Y and He B: Detection of colorectal cancer by DNA methylation biomarker SEPT9: Past, present and future. Biomark Med 8: 755-769, 2014

38. Peng HX, Yang L, He BS, Pan YQ, Ying HQ, Sun HL, Lin K, $\mathrm{Hu}$ XX, Xu T and Wang SK: Combination of preoperative NLR, PLR and CEA could increase the diagnostic efficacy for I-III stage CRC. J Clin Lab Anal 31, 2017.

39. Kinzler KW and Vogelstein B: Lessons from hereditary colorectal cancer. Cell 87: 159-170, 1996.

40. Stella S, Bruzzese A and Chiarini S: Biological bases of the colorectal adenoma-carcinoma sequence. G Chir 17: 473-476, 1996 (In Italian)

41. Takami K, Yana I, Kurahashi H and Nishisho I: Multistep carcinogenesis in colorectal cancers. Southeast Asian J Trop Med Public Health 26 (Suppl 1): S190-S196, 1995.

42. Wynter CV, Walsh MD, Higuchi T, Leggett BA, Young J and Jass JR: Methylation patterns define two types of hyperplastic polyp associated with colorectal cancer. Gut 53: 573-580, 2004

43. Wang HL, Liu P, Zhou PY and Zhang Y: Promoter methylation of the RASSF1A gene may contribute to colorectal cancer susceptibility: A meta-analysis of cohort studies. Ann Hum Genet 78 : 208-216, 2014.

44. Wang YC, Yu ZH, Liu C, Xu LZ, Yu W, Lu J, Zhu RM, Li GL, Xia XY, Wei XW, et al: Detection of RASSF1A promoter hypermethylation in serum from gastric and colorectal adenocarcinoma patients. World J Gastroenterol 14: 3074-3080, 2008.

45. Li YW, Kong FM, Zhou JP and Dong M: Aberrant promoter methylation of the vimentin gene may contribute to colorectal carcinogenesis: A meta-analysis. Tumour Biol 35: 6783-6790, 2014

46. Couraud S, Vaca-Paniagua F, Villar S, Oliver J, Schuster T, Blanché H, Girard N, Trédaniel J, Guilleminault L, Gervais R, et al: Noninvasive diagnosis of actionable mutations by deep sequencing of circulating free DNA in lung cancer from never-smokers: A proof-of-concept study from BioCAST/IFCT-1002. Clin Cancer Res 20: 4613-4624, 2014.

47. Jung K, Fleischhacker M and Rabien A: Cell-free DNA in the blood as a solid tumor biomarker-a critical appraisal of the literature. Clin Chim Acta 411: 1611-1624, 2010.

This work is licensed under a Creative Commons Attribution-NonCommercial-NoDerivatives 4.0 International (CC BY-NC-ND 4.0) License. 